\title{
Vaccination Status of Children Hospitalized for Measles: Parental Vaccination Refusal and Related Factors
}

\author{
(1) Mürşide Zengin1', (D) Emriye Hilal Yayan², (1) Mehmet Emin Düken³ \\ ${ }^{1}$ Adıyaman University Faculty of Health Sciences, Department of Child Health and Diseases Nursing, Adıyaman, Turkey \\ 2inönü University Faculty of Nursing, Department of Child Health and Diseases Nursing, Malatya, Turkey \\ ${ }^{3}$ Harran University Faculty of Health Sciences, Department of Child Health and Diseases Nursing, Şanlıurfa, Turkey
}

\begin{abstract}
Aim: This study investigated the vaccination status of those children who received inpatient treatment due to measles and explored the beliefs and practices of their parents related to the refusal of childhood vaccines.

Materials and Methods: This study was a descriptive research performed at a training and research hospital in eastern Turkey. The study data were collected from the parents of children with measles who were receiving inpatient treatment. In this study, the introductory information form and the State-Trait Anxiety Inventory were used.

Results: The results revealed that $61.8 \%$ of those children with measles had not been vaccinated against measles. Factors that played a role in the parents' vaccine refusal included family elders' unwillingness, negative media reports, the side effects of vaccines, and negative attitudes towards health care workers. Parents with poor socio-economic status, low educational status, and extended family types were found to have significantly higher rates of vaccine refusal. The parents had an average state anxiety score of $60.15 \pm 5.73$ and an average trait anxiety score of 50.21 \pm 3.33 .

Conclusion: Many factors were found to influence the causes of parents not having their children vaccinated. Community-based training is needed to address the parents' misconceptions, concerns, and lack of knowledge about vaccinations. Renewing policies on vaccinations, establishing standards, and imposing legal sanctions can be effective in reducing vaccine refusal rates.
\end{abstract}

Keywords: Child, measles, parent, vaccine hesitancy, vaccination refusal

\section{Introduction}

Vaccines are considered to be the most effective health intervention in terms of cost and reliability in preventing infectious diseases worldwide (1-3). Decreases in mortality and morbidity of many infectious diseases are seen with vaccination programmes $(4,5)$. The March 2018 report of the World Health Organization (WHO) stated that immunization prevents 2-3 million deaths per year globally (6).
Measles is a highly contagious viral infection with potentially serious complications (7,8). Although it has a safe and effective vaccine, it remains a major cause of death among young children worldwide. According to WHO data, more than 140,000 people died of measles in 2018 (9). In $2019,2,785$ cases of measles were reported in Turkey, 197,683 in the African Region, and 429,650 worldwide (10).

The WHO emphasizes the necessity of vaccination against measles for all vulnerable children and adults. It is 
also reported that standardization is required to ensure that two doses of the measles vaccine are included in the national vaccination schedule of all countries (11). The measles, mumps, and rubella vaccine (MMR) is administered to all children in Turkey in the $12^{\text {th }}$ month and in the first grade of primary education by health organizations within the scope of the expanded programme on immunization (3).

Despite the potential benefits of vaccines, the rates of parental hesitation about childhood vaccines have increased, and vaccine refusal has become increasingly common (4). Increasing cases of vaccine hesitancy and vaccine refusal lead to decreases in vaccination rates, causing an increase in the frequency of infectious diseases $(5,6)$. The re-emergence of vaccine-preventable outbreaks in many countries, including measles and pertussis, is cited as evidence of this situation (6). Measles outbreaks have also been reported in Europe due to low vaccination rates (8).

Parental vaccine hesitancy and refusal are two of the reasons for low vaccination rates in both developed and developing countries (1). The main reason reported for rejecting or interrupting vaccination is concern about the safety of one or more vaccines (12-14). This anxiety is often experienced towards the MMR vaccine. In particular, concerns have been raised over the past two decades that the MMR vaccine causes autism spectrum disorders due to their mercury content (15). This concern has led to a decrease in vaccination rates in Europe and the United States and an increase in the number of many vaccine-preventable diseases $(1,12)$. However, the reasons for parental vaccine hesitancy and refusal include information gaps, parental distrust of vaccines and the health system, negative propaganda spreading on social media (2), and the belief that vaccines overburden the immune system (15). Cases of vaccine refusal and individual vaccine exemption for non-medical and personal reasons manifest as major public health issues in the form of outbreaks, imposing considerable economic and social burdens on countries $(6,8,16)$. Only a few studies have examined the factors affecting parental attitudes and practices in vaccine hesitancy and refusal, which have become increasingly common in recent years, severely affecting public health. This study investigated the vaccination status of those children admitted due to measles and explored their parents' beliefs and practices on vaccine hesitancy and refusal.

\section{Materials and Methods}

\section{Study Design and Participants}

This descriptive research was conducted between November 2019 and March 2020 at a training and research hospital in eastern Turkey, in a province with a mixed population structure engaged primarily in seasonal agricultural labour, with high fertility rates and high poverty levels.

The inclusion criteria for this study were as follows: parents whose child; (1) (3-6 years old) was diagnosed with measles and hospitalized for treatment; (2) who could understand and speak Turkish or Kurdish; and (3) who volunteered to participate in the study. Parents whose child had a history of a diagnosed metabolic disease or psychiatric disorders were excluded from this research.

All parents meeting the inclusion criteria within the specified dates were included without sample selection. The researchers visited the inpatient ward three days a week (Monday, Wednesday, and Friday) to collect study data from the parents. The study was completed by collecting data from 89 parents.

\section{Data Collection}

The introductory information form and the State-Trait Anxiety Inventory (STAI) were used for data collection. The data were collected by the researchers using a face-to-face interview technique lasting 20 minutes on average.

The introductory information form was prepared by the researchers in line with the literature $(2,12-14,17)$. The questionnaire consisted of 28 items to evaluate the sociodemographic characteristics of the children and their parents, as well as the disease characteristics (e.g., the duration of hospitalization, the duration of the rash, and the path of transmission) and vaccination practices.

STAI: This is a self-report scale developed by Spielberger. It consists of two sub-scales (with 20 items each) that separately assess the level of state and trait anxiety. The total score of each sub-scale varies from 20 to 80 . Higher scores indicate higher levels of anxiety (18-20). This scale has been proven to be valid and reliable for the Turkish adult population by Öner and LeCompte (21). In this study, the Cronbach's alpha was 0.83 for the State Anxiety Inventory and 0.88 for the Trait Anxiety Inventory.

\section{Pilot Application}

After the data collection form was developed by the researchers, it was submitted to three faculty members, two from Paediatrics Nursing and one from Public Health Nursing-for their expert opinion. A pilot study involving 10 parents was carried out after the questionnaire was revised according to the expert opinions. In the pilot study, the questions on the data collection form were evaluated in 
terms of clarity, understandability, and deficiencies, and incomprehensible statements in the questionnaire were revised. In this way, evidence was sought for the content and face reliability and validity of the questionnaire. Then, the questionnaire was finalized and readied for the actual application. The data from the pilot study were not used due to changes and corrections to the questionnaire.

\section{Ethical Approval}

The necessary ethical permission from the İnönü University Health Sciences Non-Interventional Clinical Research Ethics Committee was obtained (ethical approval number: 445-4). The study purpose was explained to all parents who met the research inclusion criteria, and the data collection form was given. Parents were informed about the study, and those who agreed to participate voluntarily and signed the written informed consent were included in the study. After the data collection was completed, training on childhood vaccinations was provided by the researcher to address the parents' lack of knowledge under the "ethics principle of beneficence".

\section{Statistical Analysis}

SPSS Version 22.00 for Windows (IBM Corp., Armonk, United States of America) was used for statistical analysis. From the descriptive statistics, mean, standard deviation, percentage distribution, and frequency distribution were used. The Shapiro-Wilk test was implemented to determine whether the sample data were normally distributed. The chi-square test and independent samples t-test were used to compare data between those parents who had and those who did not have their child vaccinated. The data were evaluated at a 95\% confidence interval, and $\mathrm{p}<0.05$ was set as the significance level. The Cronbach's alpha reliability coefficients were calculated for the two inventories.

\section{Results}

Table I summarizes some of the sociodemographic characteristics of the children and their parents. In this study, $61.8 \%$ of the children were female $(n=55)$, and the average age was $4.75 \pm 0.93$ years ( $n=89$, one child per parent). In addition, 51 of the 89 children (57.3\%) lived in an extended family type, and $50.6 \%$ of the families had poor socio-economic status. Among the parents, 40.4\% of the mothers were housewives, $43.8 \%$ were working as agricultural labourers, and $77.6 \%$ of the fathers were factory workers. In addition, an average of $9.66 \pm 4.98$ children lived together in one household.
Table I. Distribution of some socio-demographic characteristics of the children and parents

\begin{tabular}{|c|c|c|}
\hline Variables & Mean \pm SD & Min.- Max. \\
\hline Child's age (years) & $4.75 \pm 0.93$ & $3-6$ \\
\hline Mother's age & $31.28 \pm 8.30$ & $20-49$ \\
\hline Father's age & $35.75 \pm 5.94$ & $25-48$ \\
\hline \multirow[t]{2}{*}{ Number of children } & $6.00 \pm 3.32$ & $2-13$ \\
\hline & $\mathbf{n}$ & $\%$ \\
\hline \multicolumn{3}{|l|}{ Child's gender } \\
\hline Female & 55 & 61.8 \\
\hline Male & 34 & 38.2 \\
\hline \multicolumn{3}{|c|}{ Child's educational status } \\
\hline Not going to school & 50 & 56.2 \\
\hline Pre-school & 39 & 43.8 \\
\hline \multicolumn{3}{|c|}{ Chronic disease in child } \\
\hline Yes & 18 & 20.2 \\
\hline No & 71 & 79.8 \\
\hline \multicolumn{3}{|c|}{ Mother's education level } \\
\hline Illiterate & 52 & 58.4 \\
\hline Primary education & 17 & 19.1 \\
\hline High school & 12 & 13.5 \\
\hline University & 8 & 9 \\
\hline \multicolumn{3}{|c|}{ Father's education level } \\
\hline Illiterate & 53 & 59.6 \\
\hline Primary education & 15 & 16.8 \\
\hline High school & 4 & 4.5 \\
\hline University & 17 & 19.1 \\
\hline \multicolumn{3}{|c|}{ Family socio-economic status } \\
\hline Good & 18 & 20.2 \\
\hline Middle & 26 & 29.2 \\
\hline Bad & 45 & 50.6 \\
\hline Total & 89 & 100 \\
\hline
\end{tabular}

The distribution of the reasons for measles vaccine refusal is presented in Table $\|$ and Figure 1 . Of the children included in this study, 61.8\% [95\% confidence interval (Cl): 28.4-46.1] did not get the measles vaccine. The reasons for this included family elders' unwillingness (60.7\%; 95\% Cl: 52.8-70.5), negative media reports (57.3\%; 95\% Cl: 49.4-67.1), fear of vaccine side effects (51.7\%; 95\% Cl: 42.7-61.8), a lack of home visits by midwives/nurses (42.7\%; 95\% Cl: 34.0-51.7), the belief that children die because of the vaccine $(27 \%$; $95 \% \mathrm{Cl}$ : 
17.2-37.9), a lack of reminders by midwives/nurses for the vaccine $(23.6 \% ; 95 \% \mathrm{Cl}: 16.9-36.4)$, and negative attitudes towards health care professionals (14.6\%; 95\% Cl: 7.1-26.0) (Table II, Figure 1).

Of the parents, $52.8 \%(95 \% \mathrm{Cl}: 43.8-64.5)$ reported that their child had not had any other childhood vaccinations that are included on the national vaccination calendar. The reasons for the refusal of all vaccines included unwillingness of family elders $(52.8 \%$; $95 \% \mathrm{Cl}: 43.8-64.5)$, negative media reports (50.6\%; $95 \% \mathrm{Cl}: 41.6-62.9)$, a lack of home visits by midwifes/nurses (46.1\%; 95\% Cl: 37.4-56.2), vaccine side effects (42.7\%; 95\% Cl: 31.8-52.8), the belief that children die because of vaccination (27.0\%; $95 \% \mathrm{Cl}$ : 19.1-39.0),

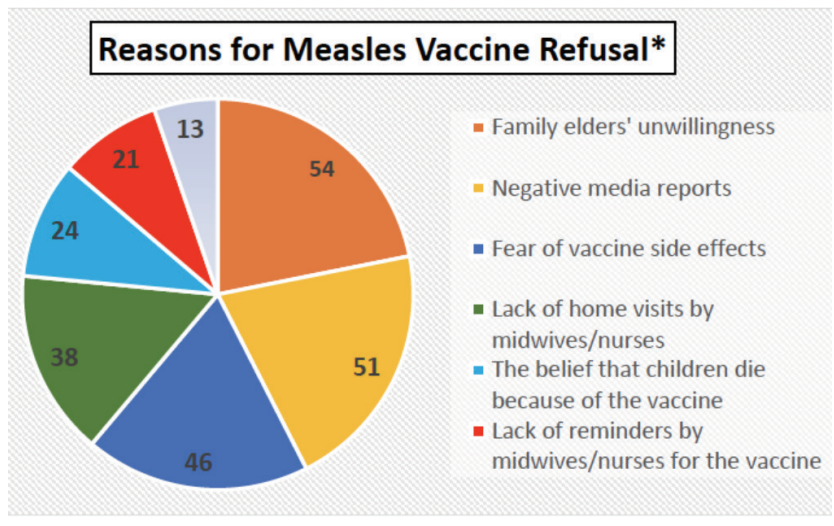

Figure 1. Reasons for measles vaccine refusal among parents *Some parents have reported more than one reasons

Table II. Reasons for measles vaccine refusal among parents

\begin{tabular}{|l|l|l|l|}
\hline & $\mathbf{n}$ & $\%$ & $\begin{array}{l}\mathbf{9 5 \%} \mathbf{C l} \\
\text { values }\end{array}$ \\
\hline Measles vaccine status & & & \\
\hline Made & 34 & 38.2 & $28.4-46.1$ \\
\hline Refused & 55 & 61.8 & $53.9-71.6$ \\
\hline Reason for vaccine refusal* & & & \\
\hline Family elders' unwillingness & 54 & 60.7 & $52.8-70.5$ \\
\hline Negative media reports & 51 & 57.3 & $49.4-67.1$ \\
\hline Fear of vaccine side effects & 46 & 51.7 & $42.7-61.8$ \\
\hline Lack of home visits by midwives/nurses & 38 & 42.7 & $34.0-51.7$ \\
\hline $\begin{array}{l}\text { The belief that children die because of } \\
\text { the vaccine }\end{array}$ & 24 & 27.0 & $17.2-37.9$ \\
\hline $\begin{array}{l}\text { Lack of reminders by midwives/nurses } \\
\text { for the vaccine }\end{array}$ & 21 & 23.6 & $16.9-36.4$ \\
\hline $\begin{array}{l}\text { Negative attitudes of health care } \\
\text { professionals }\end{array}$ & 13 & 14.6 & $7.1-26.0$ \\
\hline $\begin{array}{l}\text { *Some parents have reported more than one reasons. } \\
\text { Cl: Confidence interval }\end{array}$ & & \\
\hline
\end{tabular}

and negative attitudes towards health care professionals (27.0\%; 95\% Cl: 19.4-37.1).

Parents reported that their children had been infected with measles in the street/neighbourhood (80.9\%), park (49.4\%), hospital (37.1\%), or at school (21.3\%). The duration of hospitalization of the children was 3.92 1.34 days (range, $1-7) ; 50.6 \%$ had a rash on their skin, which continued for $1.39 \pm 1.46$ days. Among the parents, $79.8 \%$ had a fear of measles, 29.2\% reported performing "etching", a traditional method of healing the child (burning with hot iron bars on the skin to treat various diseases), 59.6\% reported that their other children also had an infectious disease, and $58.4 \%$ reported the presence of refugees in their neighbourhood; also, $52.8 \%$ reported that they would not vaccinate their children in the future.

The parents had an average state anxiety score of $60.15 \pm 5.73$ (95\% Cl: 58.53-61.30) and an average trait anxiety score of $50.21 \pm 3.33$ (95\% Cl: 49.58-50.87) (Table III).

Table IV compares some characteristics between those parents who had and those who did not have their child vaccinated against measles. The study data indicated that a significantly higher number of girls were not vaccinated than boys. Also, $10.5 \%$ of parents living in a nuclear family did not vaccinate their child, and not all parents of the extended family type had vaccinated their children. The education level of the parents, occupation of the mother, socio-economic level of the family, age of the child and the paternal age were the factors affecting the vaccination of the children against measles. The duration of the rash in children who did not get the measles vaccine was significantly higher than those who got the vaccine $(p<0.05)$. The mean anxiety scores were significantly higher in those parents who did not get their child the MMR vaccine than in those who did $(95 \% \mathrm{Cl}$ : 58.94-61.36, $\mathrm{p}=0.017$ for trait anxiety; and 95\% Cl: 49.5150.91, $p=0.001$ for state anxiety) (Table IV).

Table III. Parents' State-Trait Anxiety Inventory Scores

\begin{tabular}{|l|l|l|l|}
\hline & Mean \pm SD & Min.- Max. & 95\% Cl values \\
\hline $\begin{array}{l}\text { State anxiety } \\
\text { inventory }\end{array}$ & $60.15 \pm 5.73$ & $44-66$ & $58.53-61.30$ \\
\hline $\begin{array}{l}\text { Trait anxiety } \\
\text { inventory }\end{array}$ & $50.21 \pm 3.33$ & $40-54$ & $49.58-50.87$ \\
\hline $\begin{array}{l}\text { SD: Standard deviation, Min.: Minimum, Max.: Maximum; Cl: Confidence } \\
\text { interval }\end{array}$
\end{tabular}


Table IV. A comparison of some characteristics of parents who had and did not have vaccine their child against measles

\begin{tabular}{|c|c|c|c|}
\hline Variables & $\begin{array}{l}\text { Measles vaccine made } \\
\mathrm{n}(\%)\end{array}$ & $\begin{array}{l}\text { Measles vaccine refused } \\
\text { n (\%) }\end{array}$ & $\chi^{2} / F$ and $p$-value \\
\hline \multicolumn{4}{|c|}{ Child's gender } \\
\hline Female & $10(18.2)$ & $45(81.8)$ & $\chi^{2}=22,274^{*}$ \\
\hline Male & $24(70.6)$ & $10(29.4)$ & $p=0.000$ \\
\hline
\end{tabular}

Family type

Nucleus

Extended

34 (89.5)

$0(0)$

\begin{tabular}{|l|}
$4(10.5)$ \\
$51(100)$
\end{tabular}

$\chi^{2}=70,099^{*}$

Mother's profession

Housewive

Agricultural labourers

Factory workers

\begin{tabular}{|l|l|}
\hline $20(55.6)$ & $16(44.4)$ \\
\hline $0(0)$ & $39(100)$ \\
\hline $14(100)$ & $0(0)$
\end{tabular}

$\mathrm{p}=0.000$

Mother's education level

Illiterate

Primary education

High school

University

\begin{tabular}{|l|}
\hline $0(0)$ \\
\hline $15(88.2)$ \\
\hline $11(91.7)$ \\
\hline $8(100)$ \\
\hline
\end{tabular}

(0)

\section{Father's education level}

\begin{tabular}{|l|l|}
\hline Illiterate & 31 \\
\hline Primary education & 31( \\
\hline High school & 17( \\
\hline University &
\end{tabular}

\begin{tabular}{|l|l|l|}
\hline $3(5.7)$ & $50(94.3)$ & $\chi^{2}=78,763^{*}$ \\
\hline $11(73.3)$ & $4(26.7)$ & $\mathrm{p}=0.000$ \\
\hline $3(75.0)$ & $1(25.0)$ & \\
\hline $17(100)$ & $0(0)$ & \\
\hline
\end{tabular}

Family socio-economic status

\begin{tabular}{|c|c|c|c|}
\hline Good & $18(100)$ & $0(0)$ & $\chi^{2}=62,933^{*}$ \\
\hline Middle & $16(61.5)$ & $10(38.5)$ & $p=0.000$ \\
\hline Bad & $0(0)$ & $45(100)$ & \\
\hline Child's age (years) & $4.41 \pm 0.89$ & $4.96 \pm 0.90$ & $\begin{array}{l}F=0.628^{* *} \\
p=0.006\end{array}$ \\
\hline Mother's age & $30.52 \pm 6.84$ & $31.76 \pm 9.11$ & $\begin{array}{l}F=11,759^{* *} \\
p=0.470\end{array}$ \\
\hline Father's age & $32.64 \pm 5.06$ & $37.67 \pm 5.67$ & $\begin{array}{l}F=0.241^{* *} \\
p=0.000\end{array}$ \\
\hline Rash duration & $0.14 \pm 0.60$ & $2.16 \pm 1.30$ & $\begin{array}{l}F=29,071^{* *} \\
p=0.000\end{array}$ \\
\hline Parental state anxiety score & $58.32 \pm 7.27$ & $61.29 \pm 4.21$ & $\begin{array}{l}F=5,947^{* *} \\
p=0.017\end{array}$ \\
\hline Parental trait anxiety score & $48.73 \pm 3.11$ & $51.12 \pm 3.15$ & $\begin{array}{l}F=12,180^{* *} \\
p=0.001\end{array}$ \\
\hline
\end{tabular}

${ }^{*}$ Chi-square test was used.

${ }^{* *}$ Independent sample t-test was used 


\section{Discussion}

Although vaccines are the most successful and reliable public health intervention in history, a significant increase in parents' negative attitudes towards childhood vaccines has been noted $(4,15,17)$. This study explored the practices and attitudes of parents of children with measles in an eastern province of Turkey regarding childhood vaccination, especially the measles vaccine, and the factors affecting vaccination.

Different rates of vaccine hesitancy and refusal have been reported in the literature. In this study, $61.8 \%$ of children had not received the measles vaccine because of their parents' refusal. However, this percentage is the nonvaccination rate among those children with measles and does not reflect the overall community. Depending on the country- and time-specific hesitancy, there are differences in the rates of hesitant parents among countries (12). For the measles-rubella vaccination campaign, Krishnamoorthy et al. (13) found that almost a fifth (14.1\%) of parents expressed hesitation in vaccinating their children. In a cross-sectional study conducted by Giambi et al. (12) involving parents of 16 to 36-month-old children in Italy, the vaccine hesitancy rate was $16 \%$. Furthermore, vaccine hesitancy and refusal are more common among some faith-based groups or ethnic minorities (15). Although the present study was a regional single-centre study, the finding of the high vaccine refusal rates is remarkable. This suggests that regional differences in vaccine refusal should be considered, and regions with a high refusal rate should be evaluated separately.

Many factors play a role in parents developing a negative attitude towards childhood vaccines (12-15,22,23). A previous Turkish study found reasons such as the belief that vaccines are dangerous or useless, a distrust of vaccines, a belief in natural immunity, a belief that the child will not get sick and are not in the risk group, a religious belief, and a belief that vaccines will cause autism and infertility (14). Some parents have a negative attitude towards all vaccines, whereas others have hesitation towards only certain vaccines, especially measles. In our study, the predominant reason $(60.7 \%)$ as to why parents do not get their children vaccinated against measles was that "parents do not want children to be vaccinated". The excessive influence of family elders on parents was due to the patriarchal social structure in the study cohort, with half of the families being of an extended family type. Notably, none of the parents of the extended family type had their children vaccinated against measles. This finding demonstrates the impact of family elders on vaccine refusal.
Negative media reports were found to significantly affect $(57.3 \%)$ the refusal of the measles vaccine. Negative news and propaganda on social media have been effective in increasing vaccine refusal rates $(2,13)$. The most popular of these negative reports establishes a link between the measles vaccine and autism $(14,15)$. Jama et al. (15) reported that mothers stated that some children stop talking after the measles vaccine; based on this, they believe that the measles vaccine causes autism. Hviid et al. (24) evaluated the relationship between the MMR vaccine and autism in 657,461 children and found strong evidence that this vaccine does not increase the risk of autism. Despite studies showing that the measles vaccine is not associated with autism, the perceived relationship between the measles vaccine and autism remains a common concern influencing vaccine hesitancy and refusal $(1,2,12,14)$.

In our study, $51.7 \%$ of the parents did not vaccinate their child because of the side effects of the vaccine. However, the side effects seen after the vaccine are usually local and mild $(7,17)$. During a national catch-up measles vaccination program, 152,648 children in the 7-14 age group were vaccinated, and $30 \%$ of them reported side effects. More than half of the reported side effects were local and mild (7). These results show that parents do not have accurate knowledge of the side effects and that unfounded beliefs negatively affect the vaccination rates.

Another factor in parents' negative attitudes towards vaccination was their "negative attitudes towards health care professionals". Sabahelzain et al. (1) reported that complex factors such as religious causes, geographic barriers, old vaccine experiences (pain, fever), and the role of health workers contributed to vaccine refusal. The fact that health care professionals play an essential role in vaccine hesitancy and refusal supports our research findings $(2,12,13)$.

Other reasons for vaccine hesitancy and refusal include information gaps, vaccine safety, parental distrust of the health system, and the impact of social networks (2). In our research, $52.8 \%$ of parents reported that their child did not receive any other childhood vaccine. We determined that the reasons why parents do not vaccinate their children were in line with the reasons why they do not get the measles vaccine.

We found that vaccination rates among children were significantly lower in those parents with a low education level (Table IV). This finding is similar throughout Turkey. The rates of vaccination of children against measles decrease with decreasing levels of maternal education (25). A study of 
461 participants in India found that rates of vaccine hesitancy increased as parental education levels decreased and factors such as maternal age, maternal education level, and the profession of the parents were other sociodemographic characteristics affecting vaccine hesitancy (13). However, there are studies that indicate otherwise. One study investigating parental knowledge, attitudes, and practices about vaccination reported higher rates of vaccinated children of those parents with lower educational levels and of younger parents (4). These results show that numerous variables affect vaccine hesitancy and refusal.

In the present study, family type and socio-economic status were found to influence the parents' decision to get their child vaccinated, and all the parents with an extended family type and poor socio-economic status had failed to get their children vaccinated against measles (Table IV). Similarly, a study investigating the causes of vaccine hesitancy and refusal of parents found that those parents who rejected the vaccine had a lower socio-economic level (14). The Turkish Demographic and Health Survey also found that the children of parents with low income and those living in rural areas had lower rates of vaccination (25). In addition to the poor socio-economic level of the parents in the present study, the proportion of farmworkers was also found to be high. Families working as seasonal agricultural workers go to other cities temporarily for 4-7 months each year, live in tents, and thus have difficulty accessing health services during this process. This may contribute to the lower vaccination rates in the children of parents who work as seasonal farmer labourers.

A noteworthy result of this study is that a large proportion of parents $(52.8 \%)$ stated that they would not vaccinate their children in the future. In 2019, the WHO declared vaccine hesitancy as one of the top 10 threats to global health (13). Our research also found that a large proportion of children suffering from measles were not vaccinated. This is the negative public health implication of vaccine refusal for vaccine-preventable diseases. Some studies consider the refusal of childhood vaccines to be child neglect $(14,26)$. A study that assessed the ethics of not getting children vaccinated against measles stated that the vaccination should not be a parental choice; it should be considered a social obligation, and society is obliged to provide vaccination if the parents fail to get their children vaccinated (26).

Our data also revealed that the state anxiety levels of the parents were high $(60.15 \pm 5.73)$, and that there was a significant difference between the state and trait anxiety score averages among those parents who had and those who did not have their children vaccinated $(p<0.05)$. This condition, which indicates that parents have experienced anxiety, should not be associated with vaccine refusal because a large proportion of parents stated that they will not vaccinate their children in the future. Thus, the high levels of parental anxiety can be explained by reasons such as hospitalization, being away from work, staying at home with other children, or an interruption of their activities of daily living.

\section{Study Limitations}

This study has several limitations. First, the fact that the research only included those parents of hospitalized children diagnosed with measles is a significant limitation of this research. Second, the single-centred nature of the research conducted on participants with particular sociodemographic characteristics reduces the generalizability of the research findings. The region has a culturally mixed characteristic, with a high refugee population and a very broad perspective of socio-economics and education. Therefore, the research findings do not represent all of Turkey.

\section{Conclusions}

In this study, many factors such as family elders, media reports, vaccine side effects, and attitudes to health care workers played a role in the parents' refusal to get their child vaccinated against measles. Community-based training should be carried out to address the misconceptions, concerns, and lack of knowledge about this vaccination. Both parents and family elders must be included in this process of raising awareness of vaccines.

Health care professionals play a critical role in informing families about vaccinations. Therefore, health care professionals, who are the most reliable and vital source of information for parents, must undergo a training process and repeat this training periodically. Sharing the best evidence with the community through health care professionals can prevent the spread of misinformation.

Renewing the policies on vaccinations, establishing standards, and imposing legal sanctions can be effective in reducing vaccine refusal rates. Some standards can be established; such as proof of vaccination so that children can attend a public school or a day care facility. Future studies should involve parents of different ethnic and sociodemographic characteristics and other vaccines included in the vaccine calendar to further explore parental vaccine hesitancy and refusal. 


\section{Ethics}

Ethics Committee Approval: Necessary ethical permissions was obtained from the İnönü University Health Sciences, Non-Interventional Clinical Research Ethics Committee (approval number: 445-4).

Informed Consent: Informed written consent from parents was received through the children.

Peer-review: Externally peer-reviewed.

\section{Authorship Contributions}

Concept and Design: M.Z., E.H.Y., M.E.D., Data Collection and Processing: M.Z., M.E.D., Analysis and Interpretation: E.H.Y., M.Z., Literature Search: M.Z., E.H.Y., M.E.D., Writing: M.Z., E.H.Y., M.E.D.

Conflict of Interest: The authors declared no conflict of interest.

Financial Disclosure: The authors declared that this study received no financial support.

\section{References}

1. Sabahelzain $M M$, Moukhyer $M$, Dubé $E$, Hardan $A$, van den Borne B, Bosma $\mathrm{H}$. Towards a further understanding of measles vaccine hesitancy in Khartoum state, Sudan: A qualitative study. PLoS One 2019; 14:e0213882.

2. Jama A, Lindstrand A, Ali M, Butler R, Kulane A. Nurses' perceptions of MMR vaccine hesitancy in an area with low vaccination coverage. Pediatr Heal Med Ther 2019; 10:177-82.

3. Gülcü S, Arslan S. Vaccine application on children: A current review. Journal of Duzce University Health Sciences Institute 2018; 8:34-43.

4. Facciolà A, Visalli G, Orlando A, et al. Vaccine hesitancy: an overview on parents' opinions about vaccination and possible reasons of vaccine refusal. J Public health Res 2019; 8:13-8.

5. Gür E. Vaccine hesitancy - vaccine refusal. Turk Pediatr Ars 2019; 54:1-2.

6. Düzgün $\mathrm{MV}$, Dalgıç Aí. Can vaccine rejection, an increasing danger to public health, be prevented? I Curr Pediatr 2019; 17: 424-34.

7. Tosun S, Olut Al, Tansug N. Adverse effects of single-component measles vaccine in school children. Vaccine 2017; 35:7309-11.

8. Lo Vecchio A, Cambriglia MD, Fedele MC, et al. Determinants of low measles vaccination coverage in children living in an endemic area. Eur J Pediatr 2019; 178:243-51.

9. World Health Organization (2019) Measles. 2019 https://www. who.int/immunization/diseases/measles/en/ (accessed 2 February 2020).

10. World Health Organization (2020) Measles and Rubella Surveillance Data. https://www.who.int/immunization/ monitoring_surveillance/burden/vpd/surveillance type/active/ measles_monthlydata/en/ (accessed 18 February 2020).
11. World Health Organization. (2017) Measles vaccines: WHO position paper April 2017. http://www.who.int/wer. (accessed 12 February 2020).

12. Giambi C, Fabiani M, D'Ancona F, et al. Parental vaccine hesitancy in Italy - results from a national survey. Vaccine 2018; 36:779-87.

13. Krishnamoorthy Y, Kannusamy S, Sarveswaran G, Majella MG, Sarkar S, Narayanan V. Factors related to vaccine hesitancy during the implementation of measles-rubella campaign 2017 in rural Puducherry - A mixed-method study. I Fam Med Prim Care 2019; 8:3962-70.

14. Topçu S, Almış H, Başkan S, Turgut M, Orhon FŞ, Ulukol B. Evaluation of childhood vaccine refusal and hesitancy intentions in Turkey. Indian J Pediatr 2019; 86:38-43.

15. Jama A, Ali M, Lindstrand A, Butler R, Kulane A. Perspectives on the measles, mumps and rubella vaccination among Somali mothers in Stockholm. Int I Environ Res Public Health 2018; 15:2428.

16. Lo NC, Hotez PJ. Public health and economic consequences of vaccine hesitancy for measles in the United States. JAMA Pediatr 2017; 171:887-92.

17. Callender D. Vaccine hesitancy: More than a movement. Hum Vaccin Immunother 2016; 12:2464-8.

18. Yayan EH, Zengin M, Düken ME, Suna Dağ Y. Reducing children's pain and parents' anxiety in the postoperative period: $A$ therapeutic model in Turkish sample. I Pediatr Nurs 2020; 51: 33-8.

19. Marteau TM, Bekker H. The development of a six-item shortform of the state scale of the Spielberger State-Trait Anxiety Inventory (STAI). Br J Clin Psychol 1992; 31:301-6.

20. Julian L). Measures of anxiety: State-Trait Anxiety Inventory (STAI), Beck Anxiety Inventory (BAI), and Hospital Anxiety and Depression Scale-Anxiety (HADS-A). Arthritis Care Res (Hoboken) 2011; 63(Suppl 11):467-72.

21. Öner N, LeCompte A. Durumluk Sürekli Kaygı Envanteri El Kitabı. İstanbul, Bogaziçi Üniversitesi yayınları, 1983.

22. Napolitano F, D'Alessandro A, Angelillo IF. Investigating Italian parents' vaccine hesitancy: a cross-sectional survey. Hum Vaccin Immunother 2018; 14:1558-65.

23. Dubé E, Gagnon D, MacDonald N, Bocquier A, Peretti-Watel $P$, Verger $\mathrm{P}$. Underlying factors impacting vaccine hesitancy in high income countries: a review of qualitative studies. Expert Rev Vaccines 2018; 17:989-1004.

24. Hviid A, Hansen JV, Frisch M, Melbye M. Measles, mumps, rubella vaccination and autism a nationwide cohort study. Ann Intern Med 2019; 170:513-20.

25. Hacettepe University Institute of Population Studies. (2019). Turkey Demographic and Health Survey 2018.http://www.hips. hacettepe.edu.tr/tnsa2018/rapor/TNSA2018_ana_Rapor.pdf. (accessed 18 February 2020).

26. Bester JC. Not a matter of parental choice but of social justice obligation: Children are owed measles vaccination. Bioethics 2018; 32:611-9. 